\title{
Histological Analysis of Murine Colitis Induced by Dextran Sulfate Sodium of Different Molecular Weights
}

\author{
Shuji KITAJ IMA, Shigenobu TAKUMA, and Masatoshi MORIMOTO
}

Center for Laboratory Animals, Saga Medical School, 5-1-1 Nabeshima, Saga 849-8501, Japan

\begin{abstract}
In this study, we examined the relationship between the molecular weight of dextran sulfate sodium (DSS) and the features of colitis in a DSS-induced mouse model of human ulcerative colitis. DSS at three different molecular weights, $5 \mathrm{kD}, 40 \mathrm{kD}$ and $500 \mathrm{kD}$, was used in this study. DSS was administered in drinking water at $5 \%(w / v)$ to 6-7-weekold female BALB/C mice. After 7 days of treatment with DSS, the large intestine was examined histopathologically. Colitis was characterized by a loss of crypts, infiltration of inflammatory cells into the mucosa and submucosa, edema of the submucosa, erosion and ulceration and was observed in mice given the $5 \mathrm{kD}$ and $40 \mathrm{kD}$ forms but not the $500 \mathrm{kD}$. In the $5 \mathrm{kD}$ group, colitis was observed predominantly in the cecum and upper colon. Colitis in the $40 \mathrm{kD}$ group was more severe than that in the $5 \mathrm{kD}$ group, and in the $40 \mathrm{kD}$ group it was more severe in the lower colon than in the upper colon. These findings suggest the molecular weight of DSS to be an important factor in the murine model of colitis.
\end{abstract}

Key words: Colitis, DSS, molecular weight, mouse

\section{Introduction}

It is known that oral administration of dextran sulfate sodium (DSS), a sulfated polysaccharide, induces colitis in experimental animals such as mice $[1,4,15$, $20,24,28]$, rats $[13,27]$, guinea pigs $[11,14]$ and hamsters [23], and such colitis is considered an animal model of human ulcerative colitis (UC) $[4,13,20,24$, 27]. A difference in susceptibility to DSS-induced colitis among species has been reported. For instance, guinea pigs show high susceptibility, and colitis develops primarily in the cecum $[11,14]$, but mice and rats develop lesions mainly in the colon $[4,24]$. Furthermore, in inbred strains of mice, a different susceptibility to DSS-induced colitis was recently reported [20].
To induce colitis, DSS at different molecular weights has been used [1, 4, 11, 13-15, 20, 23, 24, 27, 28]. The molecular weight of DSS is considered an important factor in the induction of colitis in the rodents [1, 9]. To our knowledge, however, there have been no comparative studies of the features of colitis induced by DSS at different molecular weights. To understand the mechanism underlying the colitis in this model, it is important to clarify the relationship between the molecular weight of DSS and the features of colitis. In this study, we histopathologically examined the features of colitis induced in mice by DSS of different molecular weights. 


\section{Materials and Methods}

Animals: Female BALB/c Cr Slc mice (Japan SLC Co., Shizuoka, Japan) aged 6-7 weeks were used in this study. The mice were fed an autoclaved commercial diet (CA-1; Japan CLEA, Tokyo, Japan) and given drinking water ad libitum. Five animals were housed in each cage. The animal room was maintained at $22 \pm$ $2{ }^{\circ} \mathrm{C}$ with $55 \pm 5 \%$ humidity. The room was illuminated for $12 \mathrm{hr}$ each day.

Induction of colitis: DSS at three different molecular weights, $5 \mathrm{kD}$ (Wako Pure Chemical Industrial, Ltd., Osaka, Japan), 40 kD (ICN Biomedicals Inc., CA, USA) and $500 \mathrm{kD}$ (Sigma Chemical Co., MO, USA), were used in this study. Sulfur content of these sulfated polysaccharides was determined by Dodgson's turbidimetric method [5]. Sulfur content of the $5 \mathrm{kD}, 40 \mathrm{kD}$ and $500 \mathrm{kD}$ forms was $18.3 \pm 1.5 \%$ (mean $\pm \mathrm{SE}$ ), 17.2 $\pm 2.1 \%$ and $17.5 \pm 1.5 \%$, respectively (no statistical differences). Mice were divided into four groups of 5 each. Group A comprised mice who were given only distilled water (controls); Group B comprised mice who were given $5 \mathrm{kD}$; Group $\mathrm{C}$ comprised mice who were given $40 \mathrm{kD}$; and Group $\mathrm{D}$ comprised mice who were given $500 \mathrm{kD}$. To induce colitis, DSS was dissolved in drinking water to $5 \%(\mathrm{w} / \mathrm{v})$, which was administered to each group for 7 days. This study design was approved by the Saga Medical School Animal Care and Use Committee and followed the Saga Medical School guidelines for animal experimentation.

Histological evaluation of colitis: After 7 days of DSS administration, the mice were killed by cervical dislocation of the spine, and the cecum, colon, liver and mesenteric lymph nodes (MLN) were removed. The cecum and colon were fixed in $10 \%$ neutral-buffered formalin. After fixation, the colon was divided into three equal segments: proximal colon, middle colon and distal colon. Three or four transverse sections from each segment were cut in equal intervals. These specimens were embedded in paraffin, and sections were cut and stained with haematoxylin-eosin (H-E).

Colitis was graded for severity according to mucosal damage (D) based on the method of Cooper et al. [4] and extension of the lesion (E). Both are detailed in Table 1. The histological index (HI) was calculated as (D) plus (E). HI was expressed as the mean of the score for each segment, the cecum, proximal, middle and distal colon. All slides were scored blindly.

Histochemical detection of sulfated polysaccharides: The liver and MLN were fixed in Carnoy's solution and embedded in paraffin. To identify the sulfated polysaccharides by metachromasia, specimens were stained with toluidine blue at pH 2.5 [15, 25].

Isolation of sulfated polysaccharides from feces: $\mathrm{Fe}-$ ces were collected 3 days after administration of DSS and stored in cold acetone at $-20^{\circ} \mathrm{C}$ until analysis. The feces were dried and rehydrated $(50 \mathrm{mg} / \mathrm{ml})$ at $4^{\circ} \mathrm{C}$ in 0.1 $\mathrm{M}$ sodium acetate buffer ( $\mathrm{pH} 5.0$ ) containing $5 \mathrm{mM}$ EDTA. After $24 \mathrm{hr}$, papain (Sigma Chemical Co.) was added to the sample at $10 \mathrm{mg} / \mathrm{ml}$ and incubated at $60^{\circ} \mathrm{C}$ for $24 \mathrm{hr}$. The mixture was then centrifuged at 3000 rpm for $30 \mathrm{~min}$, and the supernatant was collected.

Dimethylmethylene blue (DMB) assay: The concentration of sulfated polysaccharides was determined with a 1,9-dimethylmetylene blue (DMB) assay [6]. The DMB solution was prepared by dissolving $16 \mathrm{mg}$ DMB, $3.04 \mathrm{~g}$ glycine, $2.37 \mathrm{~g}$ sodium chloride, and $95 \mathrm{ml} 0.1$ $\mathrm{M}$ hydrochloric acid in $1000 \mathrm{~m} l$ distilled water. The

Table 1. Histological grading of colitis

\begin{tabular}{lcl}
\hline Feature & Score & \multicolumn{1}{c}{ Description } \\
\hline Damage & 0 & None \\
& 1 & Loss of the basal 1/3 of the crypt \\
& 2 & Loss of the basal $2 / 3$ of the crypt \\
& 3 & Loss of entire crypt but intact surface epithelial cells \\
& 4 & Loss of both the entire crypt and the surface epithelial cells (erosion) \\
Extension & 0 & None \\
& 1 & Focal \\
& 2 & Lesions involving $1 / 3$ of the intestine \\
& 3 & Lesions involving $2 / 3$ of the intestine \\
& 4 & Lesions involving the entire intestine \\
\hline
\end{tabular}


$\mathrm{pH}$ was adjusted to 3.0. For this assay, $10 \mu l$ of each sample was mixed with $250 \mu l$ of DMB solution at room temperature, and the absorbance was measured immediately at $525 \mathrm{~nm}$. Standard curves were prepared for each molecular weight.

Polyacrylamide gel electrophoresis (PAGE): The molecular weights of the sulfated polysaccharides in the feces were estimated by PAGE $[7,8]$. Samples $(10$ $\mu \mathrm{g})$ were applied to $6 \%$ polyacrylamide slab gels at $200 \mathrm{~mA}$ for $45 \mathrm{~min}$ with a $0.1 \mathrm{M}$ phosphate buffer $(\mathrm{pH}$ 11.5 ) containing $0.125 \mathrm{M}$ formic acid. After electrophoresis, the gel was stained with $0.1 \%$ toluidine blue in $1 \%$ acetic acid.

Statistical analysis: Data are expressed as the mean \pm SE. Statistical analysis was performed by the Kuruskal-Wallis test. When a difference was significant, the Wilcoxon signed ranks test was used as a post hoc test to determine the significance of the differences in multiple comparisons. A $p$ value of $<0.05$ was considered statistically significant.

\section{Results}

Histological features of colitis: After 7 days of DSS administration, colitis was observed in groups B (5 kD DSS) and C (40 kD DSS). By histological examination, the features of colitis were characterized as a loss of crypts, infiltration of inflammatory cells into the mucosa and submucosa, edema of the submucosa, erosion and ulceration (Fig. 1). The histological changes in group B were similar to those in group C, but the severity and main site of the colitis in these two groups were different. In group B, relatively patchy lesions were observed mainly in the cecum and upper colon. In group $\mathrm{C}$, the colitis was diffuse, and the most severe colitis was observed in the lower colon. Colitis was
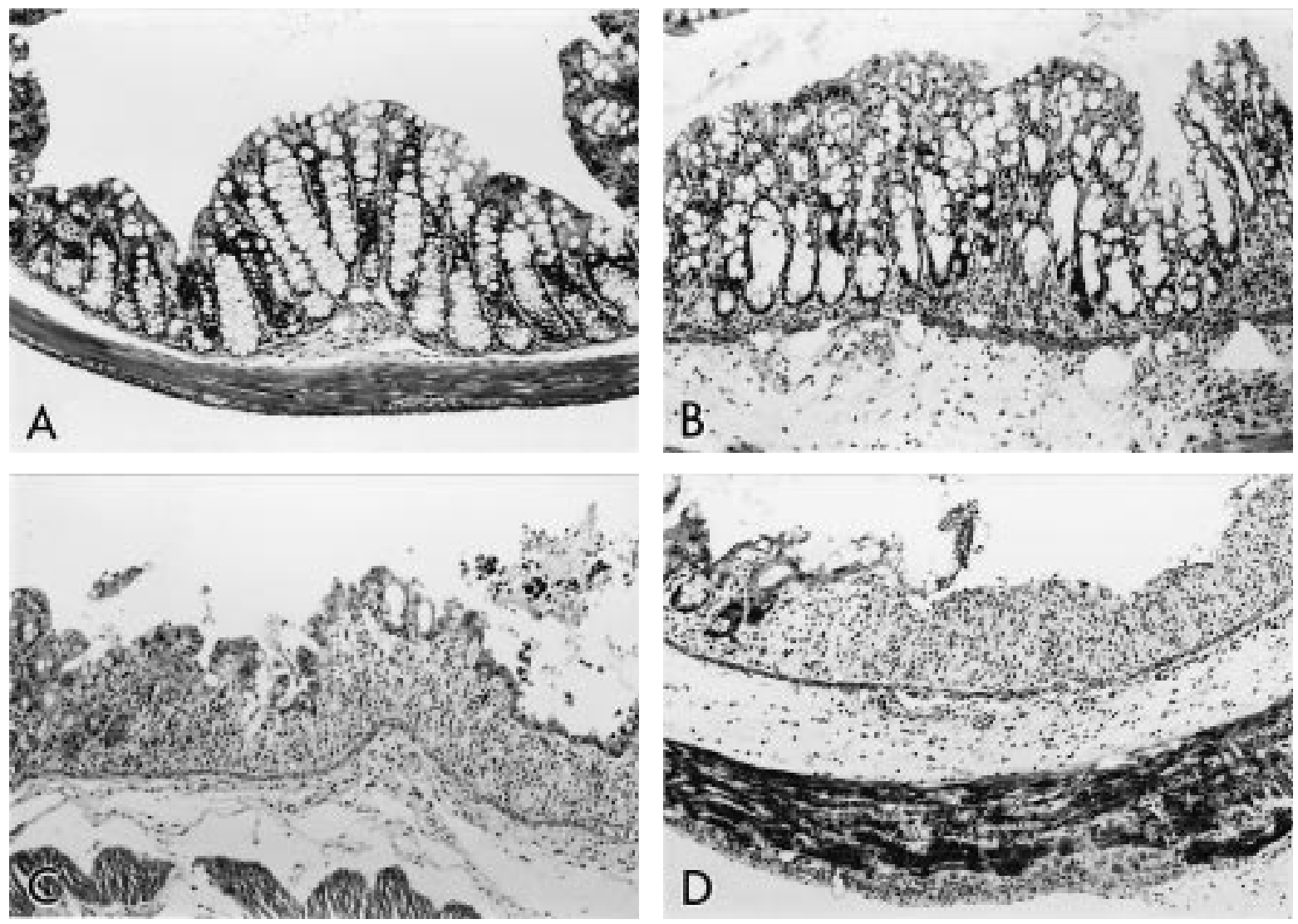

Fig. 1. Histological features of colitis induced by DSS. A) Control (damage score 0). B) Loss of basal 1/3 of the crypt (damage score 1). C) Loss of the entire crypt but intact surface epithelial cells (damage score 3). D) Loss of both the entire crypt and the surface epithelial cells (damage score 4 ). Photographs are of the middle colon of a control mouse (A) and of mice treated with $40 \mathrm{kD}$ DSS $(\mathrm{B}, \mathrm{C}, \mathrm{D})$. H-E stain, $\times 33$. 
Table 2. Histological index (HI) of colitis induced by DSS at three different molecular weights

\begin{tabular}{crlllll}
\hline \multirow{2}{*}{ Group } & \multirow{2}{*}{$\begin{array}{c}\text { MW of } \\
\text { DSS }\end{array}$} & Cecum & \multicolumn{3}{c}{ Colon } & \multirow{2}{*}{ Total } \\
\cline { 3 - 5 } & & & Proximal & Middle & Distal & \\
\hline A & & $0.60 \pm 0.32$ & $0.27 \pm 0.27$ & $0.27 \pm 0.18$ & $0.13 \pm 0.13$ & $0.31 \pm 0.12$ \\
B & $5 \mathrm{kD}$ & $5.20 \pm 0.15^{\mathrm{a}, \mathrm{x})}$ & $4.27 \pm .021^{\mathrm{b}, \mathrm{x})}$ & $1.80 \pm 0.39^{\mathrm{y})}$ & $1.07 \pm 0.32^{\mathrm{y})}$ & $3.08 \pm 0.21^{\mathrm{x})}$ \\
$\mathrm{C}$ & $40 \mathrm{kD}$ & $4.73 \pm 0.21^{\mathrm{c}, \mathrm{x})}$ & $3.93 \pm 0.30^{\mathrm{x})}$ & $5.27 \pm 0.28^{\mathrm{d}, \mathrm{z})}$ & $5.93 \pm 0.44^{\mathrm{e}, \mathrm{z})}$ & $4.97 \pm 0.18^{\mathrm{z})}$ \\
$\mathrm{D}$ & $500 \mathrm{kD}$ & $0.80 \pm 0.43$ & $0.53 \pm 0.36$ & $0.53 \pm 0.36$ & $0.13 \pm 0.13$ & $0.50 \pm 0.17$ \\
\hline
\end{tabular}

Data are expressed as the mean \pm SE. a) Significantly different from the proximal, middle and distal colons in the same group $(p<0.01)$. ${ }^{\text {b) }}$ Significantly different from the middle and distal colons in the same group $(p<0.01)$. ${ }^{\text {c) }}$ Significantly different from the proximal colon in the same group $(p<0.05)$. d) Significantly different from the proximal colon in the same group $(p<0.01)$. e) Significantly different from the cecum $(p<0.05)$ and proximal colon $(p<0.01)$ in the same group. x) Significantly different from that of groups $\mathrm{A}$ and $\mathrm{D}(p<0.01)$. ${ }^{\mathrm{y})}$ Significantly different from that of groups $\mathrm{A}$ and $\mathrm{D}$ $(p<0.05) .{ }^{z)}$ Significantly different from that of groups A, B and $\mathrm{D}(p<0.01)$.
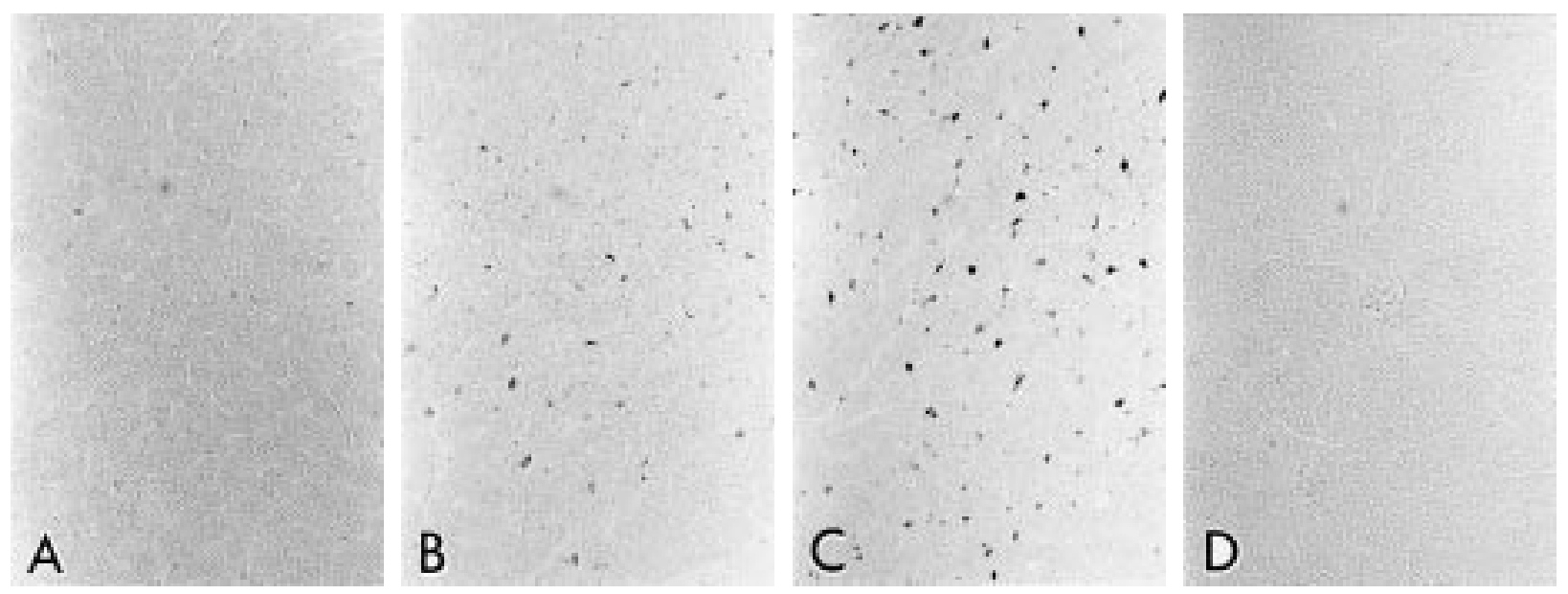

Fig. 2. Sulfated polysaccharides in the liver after 7 days of DSS administration. Toluidine blue staining ( $\mathrm{pH} 2.5)$ revealed metachromatic substances in the cytoplasm of Kupffer cells (B, C). A) Control mice. B) MW=5 kD. C) MW=40 kD. D) MW=500 kD. Toluidine blue stain $(\mathrm{pH} 2.5), \times 66$.

not observed in either group A or D (500 kD DSS).

Comparison by histological index (HI): The HI for each group is shown in Table 2. In group B, the HI of the cecum was significantly higher $(p<0.05)$ than that of the proximal colon, middle colon or distal colon, and the HI of the proximal colon was significantly higher $(p<0.01)$ than that of the middle colon or distal colon. In group $\mathrm{C}$, the $\mathrm{HI}$ of the middle colon was significantly higher $(p<0.01)$ than that of the proximal colon, and the HI of the distal colon was significantly higher than that of the cecum $(p<0.05)$ or proximal colon $(p<0.01)$. The most severe colitis observed in group B was located in the cecum, and that in group $\mathrm{C}$ was in the distal colon. Moreover, when comparing groups B and
$\mathrm{C}$, the $\mathrm{HI}$ values in the middle colon, distal colon and the total of group $\mathrm{C}$ were significantly higher $(p<0.01)$ than those values in group B. The HIs in all segments in both groups $\mathrm{B}$ and $\mathrm{C}$ were significantly higher $(p<0.05)$ than those in groups A and D. There was no statistical difference between groups A and D.

Detection of sulfated polysaccharides in the liver and $M L N$ : Uptake and deposition of sulfated polysaccharides after oral administration of DSS were examined histochemically in the liver and MLN. Sulfated polysaccharides showing metachromatic reactions with toluidine blue stain were detected in groups $\mathrm{B}$ and $\mathrm{C}$ (Figs. 2B, C) after 7 days of DSS administration. No metachromatic reactions were observed (Figs. 2A, D) 


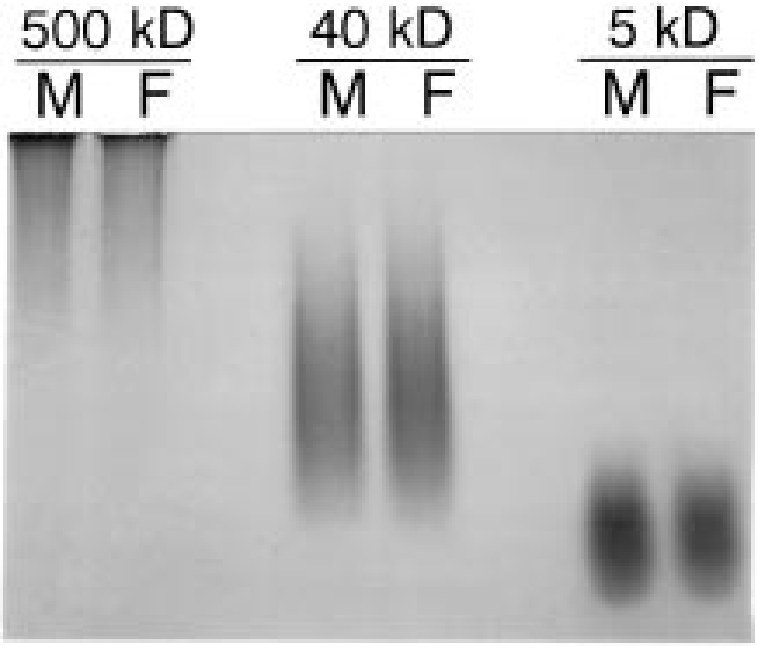

Fig. 3. PAGE of sulfated polysaccharides in the feces of mice given DSS of different molecular weights. No degraded sulfated polysaccharides were detected in the feces of mice treated with DSS at the three different molecular weights. M, DSS in drinking water. F, sulfated polysaccharides in feces of mice after administration of DSS.

in the liver in groups A and D. The metachromatic substances were visible as large granules and were observed mainly in the cytoplasm of Kupffer cells in the liver and in mononuclear cells in the subcapsular sinus of the MLN.

Molecular weights of sulfated polysaccharides in feces: We determined by PAGE whether orally-administered DSS was degraded to a smaller molecular weight in the gastrointestinal lumen. DSS at the different molecular weights of $5 \mathrm{kD}, 40 \mathrm{kD}$, and $500 \mathrm{kD}$ showed unique electrophoretic patterns corresponding to the molecular weight. The electrophoretic patterns of sulfated polysaccharides isolated from feces 3 days after administration of DSS were similar to those for DSS before administration (Fig. 3). Smaller molecular weight of sulfated polysaccharides was not detected. A significant amount of sulfated polysaccharides was not recovered from the feces of control mice.

\section{Discussion}

Spontaneous [3, 19] and drug-induced forms of UC in animals have been used as models for human UC $[18,21,22,24,29]$. There have been recent reports of knockout mice that develop colitis $[16,26]$. These animal models have been used to study the mechanisms of inflammatory bowel disease and the therapeutic effects of anti-inflammatory agents. The DSS-induced colitis model has some advantages when compared to other models of colitis. For example, an acute, chronic, or relapsing model can be produced easily by changing the concentration and cycle of administration of DSS [24]. Moreover, dysplasia that resembles the clinical course of human UC occurs frequently in the chronic phase of DSS-induced colitis [4, 24], but the exact mechanisms of induction of colitis in this model are still unknown.

Studies of the effect of the molecular weight of DSS on the induction of colitis or carcinogenicity in the rodent model were reported by Axelsson et al. [1] and Hirono et al. [9]. Axelsson et al. [1] suggested that a high sulfate content per molecule of DSS is important for the induction of colitis. They observed a significant reduction in colitis-induction when the sulfur content is below $16.6 \%$, and augmentation of inflammatory activity with increasing molecular weights. Hirono et al. [9] reported a relationship between the molecular weight of DSS and carcinogenicity in rats. They found that DSS of larger or smaller molecular weights had no carcinogenic activity when DSS at three different molecular weights, $9.5 \mathrm{kD}, 54 \mathrm{kD}$, and 520 $\mathrm{kD}$, was administered to rats at $2.5 \%$ for 480 days. These studies indicate that the molecular weight of DSS is an important factor in the induction of colitis and colonic tumors in rodents.

In this study we showed that the severity and primary location of colitis differ with the administration of DSS at different molecular weights for 7 days in mice. In mice given the $5 \mathrm{kD}$ form, colitis is observed predominantly in the cecum and upper colon. In contrast, in mice treated with $40 \mathrm{kD}$ DSS, colitis is more prominent in the lower colon. The colitis induced by $40 \mathrm{kD}$ DSS is more severe than that induced by $5 \mathrm{kD}$ DSS, but no colitis was observed in the mice given 500 kD DSS in this study.

It is possible that the lack of colitis in mice treated with $500 \mathrm{kD}$ DSS is due to the high molecular weight preventing passage of the molecule through the mucosal membrane. After 7 days of treatment with DSS, metachromatic substances were observed in hepatic Kupffer cells in mice given $5 \mathrm{kD}$ or $40 \mathrm{kD}$ DSS but not in those given $500 \mathrm{kD}$ DSS. The metachromatic stain- 
ing by toluidine blue occurs not only with externally administered sulfated polysaccharide such as DSS but also with endogenous mast cell granules, but it is possible to distinguish administered sulfated polysaccharide from mast cell granules [15]. The metachromatic substance in the cytoplasm of the macrophages is larger than the granules in mast cells [15]. Based on our previous study [15] that indicated that DSS after oral administration during the acute phase of colitis is taken up by mononuclear phagocytosis system in the liver and MLN, we did a histochemistry study on the liver and MLN in this study.

The electrophoresis analysis demonstrated that the molecular weights of DSS detected in the feces were the same as those of the DSS in drinking water before administration. Moreover, the molecular weight of DSS detectable by histochemistry is considered to be large [25]. These data suggest that the majority of DSS administered orally is not degraded into smaller fragments in the gastrointestinal lumen, and DSS may pass intact through the mucosal membrane.

In the difference in severity of colitis caused by the 5 $\mathrm{kD}$ and $40 \mathrm{kD}$ DSS molecules, the sulfur content per molecule may be an important factor in the induction of colitis as Axelsson et al. [1] reported. They suggested that larger molecular weights of DSS may be desirable to induce severe colitis, since higher molecular weight forms of DSS contain more sulfur per molecule.

In the gastrointestinal tract, mucosal epithelial cells form a structural barrier composed of mucus and tight junctions that protects against luminal substances that are harmful to the host $[2,10,12]$. It has been reported that in the large intestine, the cecum is the most permeable portion, and it is a weak point for luminal substances in guinea pigs [14]. Other in vitro studies of the large intestines with various test markers showed that the proximal colon is more permeable than the distal colon $[12,17,28]$. The most permeable portion of the colon is thought to be the region where a large amount of DSS can pass through the mucosal membrane, but in the present study the most severe colitis induced by $40 \mathrm{kD}$ DSS occurred in the distal colon. We can't explain this contradiction, but this phenomenon may be due to the differences in molecular weights and not in the degree of sulfation because the sulfur contents of the three different molecular weights of DSS used in this study were approximately equal. This mouse model of colitis will be a unique tool for analyzing the relationship between the molecular weights of toxic substances and mucosal permeability as a function of the mucosal barrier in the large intestine.

In conclusion, we showed that the severity and regional localization of colitis were different for three different molecular weights of DSS used to induce colitis in mice. These findings suggest that the molecular weight of DSS as well as the species difference in susceptibility and strains are important factors in the DSS-induced murine colitis model.

\section{Acknowledgment}

We thank Mr. K. Tomoda of the Center for Laboratory Animals, Saga Medical School, for technical assistance.

\section{References}

1. Axelsson, L.G., Landström, E., Lundberg, C., and BylundFellenius, A.C. 1996. The degree of sulfate content and the molecular weight of dextran sulfate and carrageenan are important for the induction of colitis in mice. Gastroenterology 110: A858 (Abstract).

2. Bjarnason, I. 1994. Intestinal permeability. Gut suppl. 1: s18-s22.

3. Chalifoux, L.V. and Bronson, R.T. 1981. Colonic adenocarcinoma associated with chronic colitis in cottontop marmosets, Saguinus oedipus. Gastroenterology 80: 942-946.

4. Cooper, H.S., Murthy, S.N.S., Shah, R.S., and Sedergran, D.J. 1993. Clinicopathologic study of dextran sulfate sodium experimental murine colitis. Lab. Invest. 69: 238-249.

5. Dodgson, K.S. 1961. Determination of inorganic sulphate in studies on the enzymic and non-enzymic hydrolysis of carbohydrate and other sulphate esters. Biochem. J. 78: 312-319.

6. Farndale, R. W., Buttle, D. J., and Barrett, A. J. 1986. Improved quantitation and discrimination of sulphated glycosaminoglycans by use of dimetylmetylene blue. Biochim. Biophys. Acta 883: 173-177.

7. Gumarães, M.A.M. and Mourão, P.A.S. 1997. Urinary excretion of sulfated polysaccharides administered to Wistar rats suggests a renal permselectivity to these polymers based on molecular size. Biochim. Biophys. Acta 1335: 161-172.

8. Hilborn, J.C. and Anastassiadis, P.A. 1969. Acrylamide gel electrophoresis of acidic mucopolysaccharides. Anal. Biochem. 31: 51-55.

9. Hirono, I., Kuhara, K., Yamaji, T., Hosaka, S., and Golberg, L. 1983. Carcinogenicity of dextran sulfate sodium in relation to its molecular weight. Cancer Letters 18: 29-34. 
10. Hollander, D. 1992. The intestinal permeability barrier. A hypothesis as to its regulation and involvement in Crohn's disease. Scand. J. Gastroenterol. 27: 721-726.

11. Hoshi, O., Iwanaga, T., and Fujino, M.A. 1996. Selective uptake of intraluminal dextran sulfate sodium and senna by macrophages in the cecal mucosa of the guinea pig. $J$. Gastroenterol. 31: 189-198.

12. Hosoya, K., Kubo, H., Natsume, H., Sugibayashi, K., Morimoto Y., and Yamashita, S. 1993. The structural barrier of absorptive mucosa: site difference of the permeability of fluorescein isothiocyanate-labelled dextran in rabbits. Biopharm. Drug Dispos. 14: 685-696.

13. Howarth, G.S., Xian, C.J., and Read, L.C. 1998. Insulinlike growth factor-I partially attenuates colonic damage in rats with experimental colitis induced by oral dextran sulphate sodium. Scand. J. Gastroenterol. 33: 180-190.

14. Iwanaga, T., Hoshi, O., Han, H., and Fujita, T. 1994. Morphological analysis of acute ulcerative colitis experimentally induced by dextran sulfate sodium in the guinea pig: some possible mechanisms of cecal ulceration. J. Gastroenterol. 29: 430-438.

15. Kitajima, S., Takuma, S., and Morimoto, M. 1999. Tissue distribution of dextran sulfate sodium (DSS) in acute phase of murine DSS-induced colitis. J. Vet. Med. Sci. 61: 6770.

16. Kühn, R., Lohler, J., Rennick, D., Rajewsky, K., and Müller, W. 1993. Interleukin-10 deficient mice develop chronic enterocolitis. Cell 75: 263-274.

17. Lange, S., Delbro, D.S., and Jennishe, E. 1994. Evans blue permeation of intestinal mucosa in the rat. Scand. J. Gastroenterol. 29: 38-46.

18. MacPherson, B.R. and Pfeiffer, C.J. 1978. Experimental production of diffuse colitis in rats. Digestion 17: 135150.

19. Madara, J.L., Podolsky, D.K., King, N.W., Sehgal, P.K., Moore, R., and Winter, H.S. 1985. Characterization of spontaneous colitis in cotton-top tamarin (Saguinus oedipus) and its response to sulfasalazine. Gastroenterology 88: 1319.

20. Mähler, M., Bristol, I.J., Leiter, E.H., Workman, A.E., Birkenmeier, E.H., Elson, C.O., and Sundberg, J.P. 1998. Differential susceptibility of inbred mouse strains to dextran sulfate sodium-induced colitis. Am. J. Physiol. 274: G544G551.

21. Marcus, R. and Watt, J. 1969. Seaweeds and ulcerative colitis in laboratory animals. Lancet 2: 489-490.

22. Morris, G.P., Beck, P.L., Herridge, M.S., Depew, W.T., Szewczuk, M.R., and Wallace, J.L. 1989. Hapten-induced models of chronic inflammation and ulceration in the rat colon. Gastroenterology 96: 795-803.

23. Ohkusa, T. 1985. Production of experimental ulcerative colitis in hamsters by dextran sulfate sodium and change in intestinal microflora. Jpn. J. Gastroenterology 82: 1327-1336.

24. Okayasu, I., Hatakeyama, S., Yamada, M., Ohkusa, T., Inagaki, Y., and Nakaya, R. 1990. A novel method in the induction of reliable experimental acute and chronic ulcerative colitis in mice. Gastroenterology 98: 694-702.

25. Pearse, A.G.E. 1985. Inorganic constituents and foreign substances. pp. 1009-1010. In: Histochemistry Theoretical and Applied, 4th edt., Churchill Livingstone, London.

26. Sadlack, B., Merz, H., Schorle, H., Schimpl, A.C., and Horak, I. 1993. Ulcerative colitis-like disease in mice with a disrupted interleukin-2 gene. Cell 75: 253-261.

27. Takizawa, H., Asakura, H., Sasakawa, T., Bannai, H., and Nomoto M. 1995. Immunological studies of the mucosa in colitis induced by sodium dextran sulfate in rats. Adv. Muc. Immunol. 371B: 1383-1387.

28. van Meeteren, M.E., van Bergeijk, J.D., van Dijk, A.P., Tak C.J., Meijssen, M.A., and Zijlstra, F.J. 1998. Intestinal permeability and contractility in murine colitis. Mediators Inflamm. 7: 163-168.

29. Watt, J. and Marcus, R. 1972. Ulceration of the colon in rabbits fed sulfated amylopectin. J. Pharm. Pharmacol. 24: 68-69. 